\title{
Do students enter medicine for money and prestige or to be of service?
}

\author{
— Cite as: CMAJ 2018 February 26;190:E229-30. doi: 10.1503/cmaj.109-5560
}

Posted on cmajnews.com on Feb.6, 2018.

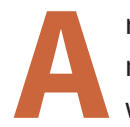
recent survey suggested that most Canadian medical students were motivated to enter medicine by "external" factors such as prestige and money. Associations that represent Canadian medical students and faculties say that although the survey highlights some shortfalls of admission processes for medical schools, the methodology and motivation of the survey company may be suspect.

Sixty-eight percent of the Canadian medical students and residents who responded to the survey reported being motivated at least partly by income, status and parental pressure to enter medicine, but only $32 \%$ reported wanting to be of service as their primary motivation. The survey also found that many medical students are privileged, with almost $40 \%$ coming from households with annual incomes over $\$ 100000$. About two-thirds of the 452 respondents were medical students and a third were residents. The respondents were targeted via social media, including Facebook and LinkedIn.

Dr. Behrouz Moemeni, CEO of SortSmart, the company behind the survey, defended the sample as representative, explaining that the socioeconomic and gender breakdown of the respondents was very similar to previously published statistics on the breakdown of Canadian medical students and residents.

But according to Victor Do, western regional representative for the Canadian Federation of Medical Students, the sample is skewed toward trainees in urban areas. More than $15 \%$ of respondents came from the University of Toronto alone. Respondents from schools in the three prairie provinces made up less than $12 \%$ of the total.
More troubling for Do, however, was the line of questioning in the survey. To decipher motivation, students were asked to rate the most important reason they applied to medical school. Respondents who selected one of these three out of four options - to be a leader while enjoying a lucrative career; one or more family members are doctors or other health care professionals; and to heal and be of service, while enjoying a lucrative career - were considered to be externally motivated. Only those who chose the remaining option (to heal and be of service, even if it means to volunteer without pay) were considered to be intrinsically motivated.

"I think residents who said they wanted to be a leader, or wanted to be paid well, would still be intrinsically motivated," said Do.

According to Dr. Geneviève Moineau, president and CEO of the Association of
Faculties of Medicine of Canada (AFMC), there may be a reason for the "leading" line of questioning in the survey. "This is a company that is creating a tool for candidate selection, so they have a vested interest in suggesting there's a problem," she said.

For his part, Moemeni of SortSmart argued that students' motivation needs to be a bigger factor in the selection of medical school applicants. "We know, based on lots of evidence in the field of psychology, that motivation drives behaviour much more than academic performance and test scores," he said. Moemeni argues the score cut off for the Medical College Admission Test (MCAT) is currently too high for most medical schools.

Moineau of AFMC agrees that better ways to evaluate "humanistic" factors including "one's capacity to learn" and "the intrinsic motivation to provide care and to advance scientific discovery" are

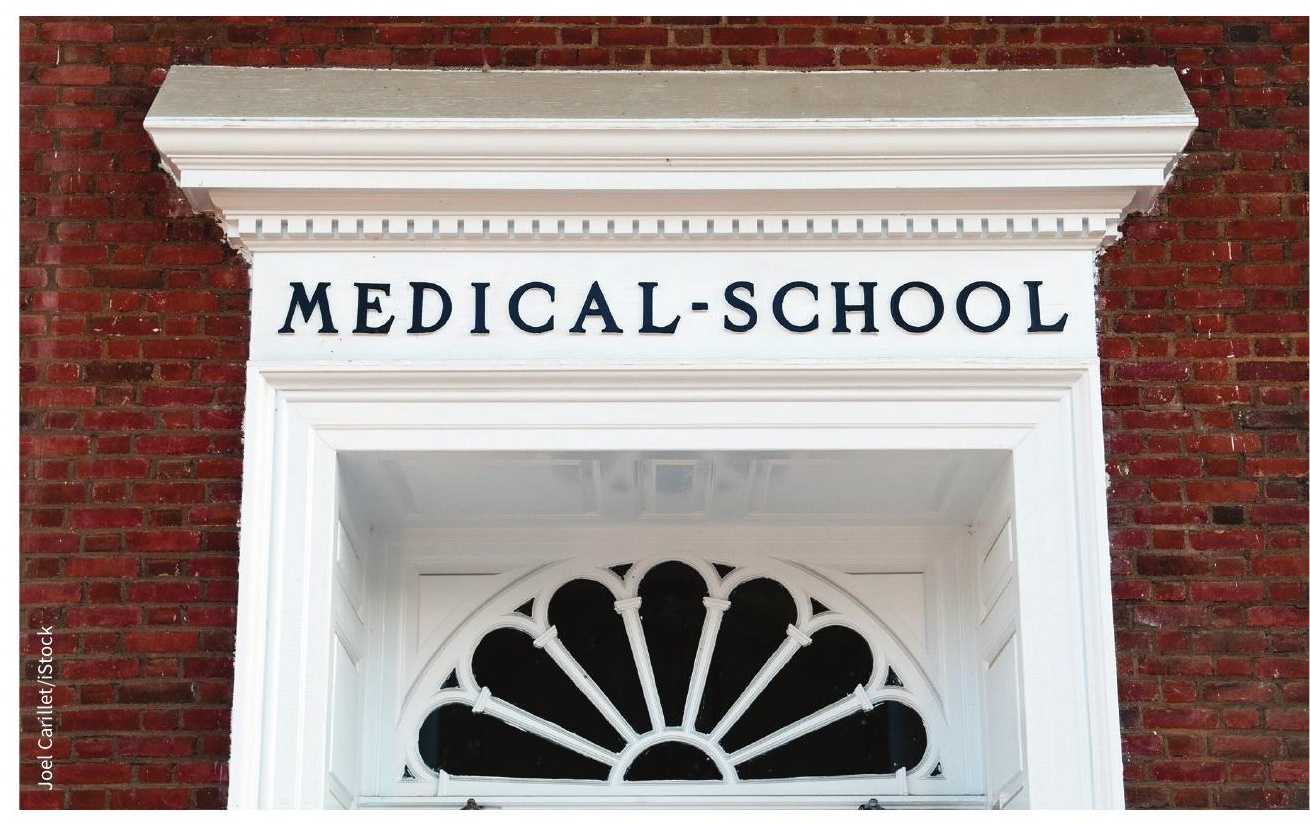

Could admission processes for Canadian medical schools be improved? 
needed. But these are difficult traits to measure in a standardized process. The AFMC recently launched a think tank to look at shortcomings in admissions processes for medical schools and identify potential improvements.

The problem highlighted in the SortSmart survey of overrepresentation of students from Caucasian and wealthier backgrounds has "been identified since the early 2000s," said Do, who added that various initiatives have been launched to improve diversity in medicine. For instance, the University of Alberta conducts outreach at junior high and high schools with large numbers of low-income students, encouraging them to consider medicine and letting them know about resources, such as a free MCAT preparatory program for low-income students.
Finding highly motivated candidates who are representative of Canada's diversity is a complex task and will require more than a better screening tool, said Do. " $A$ lot of odds are stacked against students from lower socioeconomic and rural backgrounds that prevent them from applying to medical school in the first place."

Wendy Glauser, Toronto, Ont. 